\title{
Challenges Experienced with the Implementation of Supplemental Instruction at Institutions of Higher Education
}

\author{
Matshidiso Mirriam Moleko \\ School of Education Studies, University of the Free State \\ Email: molekomm@ufs.ac.za \\ Dipane Hlalele
}

School of Education Studies, University of the Free State, Qwaqwa campus

Email: hlaleledj@qwa.ufs.ac.za

\section{Mahlomaholo Mahlomaholo}

School of Mathematics, Natural Sciences and Technology Education, University of the Free State

Email: mahlomaholomg@ufs.ac.za

Doi:10.5901/mjss.2014.v5n27p740

\begin{abstract}
This paper examines the challenges experienced with the implementation of supplemental instruction in institutions of higher education. Supplemental Instruction (SI) is a cooperative learning model designed to improve student performance in high-risk courses with a history of high failure rates. It is aimed at facilitating understanding of course content while at the same time assisting students to develop better learning skills. Although there is substantial evidence of the benefits of SI in institutions of higher education which have adopted it, there are challenges that hamper its successful implementation. The main findings in terms of the challenges were: lack of a coordinated plan; lack of articulated vision and ownership; SI leaders' inability to model effective instructional strategies; SI leaders' inability to effectively engage students in their own learning; and no feedback offered within the setup to keep stakeholders abreast and to promote individual growth
\end{abstract}

Keywords: Supplemental Instruction, Critical Emancipatory Research, Participatory Action Research

\section{Introduction}

Supplemental Instruction (SI) is a cooperative learning model designed to improve student performance in high-risk courses with a history of high failure rates (Etter, Burmeister \& Elder, 2000:355). It facilitates understanding of course content, simultaneously encouraging students to develop better learning skills (Bengesai, 2011:61). Sessions are led by senior students, who have successfully completed a high-risk course (Lockie \& Van Lanen, 2008:2), regularly on an out of class basis. Literature shows positive impact made by SI in terms of improving students' performance, reducing attrition rates and also increasing the retention rates (Arendale, 1994:1; Etter et al., 2000:356; Zaritsky \& Toce, 2006:23; Zeger, Clarke-Unite \& Smith, 2006:66). Despite evidence of these improvements, evidence also exists of instances where SI for students was not effective as in the context of this study (Wright, Wright \& Lamb, 2002:30). The biggest challenge pertains to lack of a coordinated plan which results in SI leaders in most cases going to sessions with no idea of which content/concepts to focus on during the sessions. This then leads to students not benefitting from SI sessions since their needs were not met.

It also seems as if the SI vision is not clearly articulated and owned by all the stakeholders involved and this manifests in students perceiving SI as a remedial programme meant to assist less clever students. Because of this students did not attend these sessions, as it is reported to be the case in South Africa (SA) and the United States of America (USA) (Bengesai, 2011:66; Arendale, 1994:3) as they did not want to be branded as less clever, thus leading to students not attending sessions. Students are further amenable to believing positive and negative information about the programme. In addition, some SI leaders seemed unable to model effective instructional strategies whereby instead of applying the appropriate SI instructional strategies that promote student understanding of the course, they acted as lecturers and thus did most of the talking whereas the students were supposed to do the talking. In certain instances the 
SI leaders even repeated the lectures or introduced a new topic without linking it to previous topics introduced by the lecturer, and thus confusing the students.

Moreover, some SI leaders also seemed unable to effectively engage students in their own learning. This poses a big challenge as it makes it difficult for students to understand the content and also to become independent learners. Another South African study revealed that SI leaders who could not act as facilitators in the collaboration of learning with the students made it difficult for SI to become a student learning community and also lacked the potential to increase student engagement (Bengesai, 2011: 62). Over and above, lack of feedback offered within the setup created knowledge gaps among the stakeholders and also did not enhance a critical reflection of the situation by all involved. It is also likely to fail in ensuring maximum benefit in implementation of $\mathrm{SI}$ as well as in the well round functioning of the programme. For instance, in SA like in Nigeria and USA, the evaluation took into account students' inputs/comments and their results in deciding whether the programme was effective or not. Other crucial issues such as the facilitation of large classes and timetable clashes which also came out of evaluation and which required to be dealt with were realised even though much was not done to address those issues (Fayowski \& McMillan, 2008:848; Bentley \& Hills, 2009:145; Bengesai, 2011:64). Over and above that, feedback did not seem to be shared with all the stakeholders involved.

The following sections will look at the challenges experienced during the implementation of SI for students. It should be noted however that in the context of SA and USA the students who assist other students with the learning of content are called SI leaders, which is different from Nigeria where they are called peer teachers. Therefore in the subsequent paragraphs the use of SI leaders and peer teachers will be noted in line with their contexts.

\section{Theoretical Framework}

Critical Emancipatory Research (CER) was adopted for this study because of its emphasis on power sharing among all stakeholders. Before any solution can be put in place the challenges needed to be identified, therefore a collective effort from all stakeholders was deemed of vital importance. The conditions also had to appeal to all stakeholders since CER endorsed transformation and empowerment. CER was also deemed significant for this study due to its ability to minimize hindrances that might occur when conducting the study since it promoted praxis. Through CER the researcher can interpret other people's interpretations, and make sense of them (Mahlomaholo \& Nkoane, 2002:2). Mahlomaholo and Nkoane (2002:2) also contended that the CER framework enables researchers to be analytical and to search for deeper meaning from multiple perspectives of the research question. Furthermore, CER was also deemed fit for this study because it encourages teamwork and equal power sharing wherein the researcher and the participants get to treat each other as equals with regard to the research project.

\section{Challenges Experienced with the Implementation of Supplemental Instruction at Institutions of Higher Education}

\subsection{Lack of a coordinated plan}

According to the Business Online Dictionary (2000:Online) coordination refers to the synchronisation and integration of activities, responsibilities, command and control structures to ensure that the resources of an organization are used most efficiently in pursuit of the specified objectives. This means that a coordinated plan is a plan which explicitly shows how the activities and responsibilities are being synchronised in pursuit of the specified organisation's objectives by elucidating what needs to be done, when, how and by whom. According to the Supplemental Instruction Leader Manual Guideline (SILMG) (2008:10) one of the responsibilities of both the lecturer and the SI leader is to establish a coordinated plan in terms of the content to be presented to the students, by meeting regularly prior to the SI sessions. In order for this plan to be effective the lecturer clarifies the uncertainties the SI leader may have regarding the material to be discussed during the session with the students. During such a meeting, it is expected of the SI leader to show the lecturer the handouts he/she plans to share with the students during the SI session and the lecturer is expected to assist the SI leader by making these hand-outs more appropriate to the course material. Thus the lecturer's responsibility in this case is to help the SI leader to create an effective and coordinated plan that will ensure that his/her sessions become productive and beneficial to the students.

Although the guideline encourages the establishment of a coordinated plan, evidence can be found in literature that shows how the lack of a coordinated plan leads to SI not being functional. As a result, the students do not profit from the SI sessions and their performance also does not improve. For instance, in South Africa (SA) and in the United States of America (USA), SI leaders are expected to attend all classes, take notes, complete reading assignments and do all the 
homework, just as the students enrolled in the class (Arendale, 1994:2; Congos \& Schoeps, 1993:166; Obiunu, 2008:237). The schedules for the SI leaders, however, are not integrated in the institution timetable and in many occasions these session schedules clash with their lecture schedules (classes which they have to attend as the students). This leads to them skipping sessions in certain instances and thus not helping students with content they did not understand. Furthermore, the SI leaders could not meet regularly with the lecturers in order to establish the plan. As a result, the SI leaders found themselves presenting different topics than those presented by their lecturers thus leading to students being confused.

Furthermore in SA, Nigeria and the USA, both the SI leaders and the lecturers are expected to meet regularly in order to discuss the content that should be dealt with during the sessions and other challenges experienced, ensuring effectiveness of the plan (SILMG, 2013:10, Zaritsky et al., 2006:29). However, the students who are in need of SI are usually not taking part in the meetings. In many instances, these students do not receive SI on the topics they struggle with as they were never given the opportunity to suggest topics for discussion. As a result they still experience challenges even after SI.

Drawing from the above, it is clear that lack of a coordinated plan is a common challenge in SA, Nigeria and USA. Apart from lack of coordinated plan as a challenge, lack of articulated vision and ownership seems to be the other challenge hindering the implementation of SI for first year students as explained in the next section.

\subsection{Lack of articulated vision and ownership}

According to Halligan and Donaldson (2001: Online), a well led organisation knows how to effectively communicate the vision and values to all involved. Such communication will give staff a common and consistent purpose and clear expectations that would result in them focusing on reaching the goals.

According to the SILMG (2008:3), a clearly communicated and owned vision makes it possible to achieve academic excellence. Although the guideline points to that as an advantage, literature indicates that in SA and the USA the SI vision seemed not to be clearly articulated and owned by all the stakeholders involved and that resulted in SI not being as functional as it could be. Students had negative perceptions about the programme. Most of them believed that the programme was meant for students who were mentally challenged, thus thinking it was a remedial programme. When they were asked as to why they were not attending the sessions, they either made up excuses or could not provide substantial reasons (Bengesai, 2011:66; Bentley et al, 2009:144 \& Malm, Bryngfors \& Mörner, 2012:39).

The USA seemed to experience challenges related to timetable clashes. Each SI leader was allocated two groups, $\mathrm{A}$ and $\mathrm{B}$, who he was responsible for. However, due to timetable clashes, the SI leader was often unable to attend sessions with both groups with the result that the students from group A received more benefits than students from group B. This also impacted on the performance of group B as they could not perform as well as group A (Wright et al., 2002:32). The reason for these timetable clashes is that apparently the university timetable did not include the SI sessions. This to some extent could indicate that the programme's vision was not recognised and embraced, or even owned that much by the institution; hence these clashes which could have been evaded if a valuable programme such as SI was taken seriously.

Based on the above, it is clear that in SA, Nigeria and the USA that lack of articulated vision and ownership seemed to be the cause of the non-functionality of $S I$ for first year students.

\subsection{Sl leaders' inability to model effective instructional strategies}

According to the Supplemental Instruction Supervisor Manual Guideline (SISMG) (2008:17) the SI leaders as the key role players in the programme, are expected to present an appropriate model of thinking, organisation and mastery of the discipline. The training that they undergo thus enables them to know how students learn as well as use the appropriate instructional strategies aimed at strengthening student academic performance. As a result of this, the SISMG (2008:17) indicates that students who attend the SI sessions would be able to discover the appropriate application of the study strategies as they review the course material. Although this is an ideal situation literature indicates that the SI leaders often are unable to help students integrate how-to-learn with what-to-learn, thus making it difficult for first year students to understand the course content and also to improve in their performance.

For example, in SA and the USA, the SI leaders re-lectured the students instead of facilitating the sessions by applying the principles of active collaborative learning when assisting students with mathematical concepts that they did not understand. They showed students how to solve the given mathematical problems while the students were just sitting down listening without being involved in the problem solving process. The SI leaders applied such a "teaching strategy" 
even though it was discouraged during their training. Re-lecturing thus deprived students an opportunity to benefit from active collaborative strategies which could have assisted them in better understanding first year course content (Congos et al., 1993:166; Hensen et al., 2002:250). However in Nigeria re-lecturing of the content is encouraged. The peer teachers are taught prior to the sessions and they are expected to teach their peers what they have been taught the same way as they have been taught (Bentley et al., 2009:144).

\subsection{Sl leaders' inability to effectively engage the students in their own learning}

One of the guidelines as stipulated in the SISMG (2010:10) is that students need to be engaged in activities and problem solving during the sessions. The guideline further emphasises that the students, who are engaged in the activities, should also be the ones doing most of the talking and not the SI leaders. From the Social Independence Theory (SIT) as noted in the SISMG (2010:4), such student engagement enables the students to actively construct knowledge as they work together cooperatively and interdependently. It further promotes dialogue among the students and increases student knowledge and understanding of the course. Literature shows that when the first year students are not actively engaged in their own learning their understanding of course content does not increase.

The studies conducted in SA, Nigeria and the USA revealed that the SI leaders who did not act as facilitators in the collaboration of learning with the students made it difficult for SI as a student learning community to increase student engagement (Bengesai, 2011:62, McGuire, 2006:3). Thus it became difficult for students to demonstrate understanding of the course content since they were never provided with the problems to solve as groups (on their own). Although the concept of student engagement was encouraged, research conducted in SA further revealed that on numerous occasions a large number of first year students attended the SI sessions and made collaborative working of the groups difficult. The SI leaders thus found it difficult to apply the SI techniques of collaborative learning, problem solving and student engagement since they were by no means experienced in handling such big classes (Harding et al., 2011:851).

Based on this therefore the study sought to establish ways in which the SI leaders could be empowered in order to be able to effectively engage students in meaningful learning of first year content.

\subsection{No feedback offered within the setup to keep stakeholders abreast and to promote individual growth}

The SILMG (2007:7) notes the evaluation of the programme as one of the elements of the model that must be present in order to ensure the integrity of the programme. According to the Guideline document, the programme is evaluated appropriately by assessing institutional outcome measure (e.g. final course marks, course withdrawal rates, institutional dropout rates and institutional graduation rates). On the basis of this, the SISMG (2007:46) stipulates that the Supervisor should regularly give feedback to the departments involved by having quarterly meetings with the departments' contact persons.

The SISMG (2008:47) further stipulates that observations of the SI leaders should be performed regularly and immediate feedback provided to the individual SI leaders. This will allow all stakeholders to know how things progress in the programme. The SI leaders will thus learn from the feedback and develop. While the guideline insists on feedback to be offered to the stakeholders, literature shows that no feedback is offered within the setup so to keep the stakeholders abreast and also to promote SI leaders' growth.

Most of the studies on SI indicate evaluation being performed by looking more into students' performance through the use of statistical methods, which often result in inherent self-selection bias (Bowles et al., 2008:3) in order to determine whether the programme is effective or not. The studies however do not seem to indicate how feedback was provided to the different stakeholders or the SI leaders. In other words, in cases wherein the programme could not serve best the needs of the students, the people involved could not make significant input which could have improved the programme and consequently also student performance.

From the above sections, it is clear that in SA, Nigeria and USA, lack of feedback in the setup caused nonfunctionality of SI. The stakeholders could not contribute towards improving the functionality of the programme. Based on these, the study aimed at finding better ways in which to effectively provide feedback in order to improve first year student performance.

\section{Solutions to the Problems as Experienced}

The following sections provide the solutions to the challenges (as highlighted above) that were experienced in the mentioned countries. 


\subsection{The presence of a coordinated plan}

According to the SILMG (2008:10), SI is offered only with the support of the lecturer and as such the SI leaders need to be supported by the lecturers. The support from the lecturer's side is to help the SI leaders plan and prepare for the SI sessions to ensure that the hand-outs that the SI leaders need to share with the students could be made more appropriate to the course material. Furthermore, it is to ensure that similar topics are addressed at the same time and that the same lesson outcomes are achieved. As indicated above (2.5.1) lack of a coordinated plan harmed the functionality of the programme and certain steps were taken in SA, Nigeria and USA to address that. Cooperative working was established between the lecturers and the SI leaders which resulted in a coordinated plan being established. In SA, lecturers and the SI leaders met weekly in order to draw up a common plan regarding concepts that required attention (Zeger et al., 2006:65). Similarly so, in USA lecturers and SI leaders held meetings wherein they established a common plan together (Zaritsky et al., 2006:29). In Nigeria however, no meetings were held but the course instructors responsible for the certain courses taught the peer-teachers concepts that they needed to present to the students in class, which was a way of preparing them for the role as peer teachers (Bentley et al., 2009:144).

From the above it is clear that the establishment of a coordinated plan was similar between SA and the USA. The SI leaders knew which mathematical concepts they needed to deal with, how and when through the weekly meeting they held with their lecturers. However, this seemed to be different from how the plan was established in Nigeria where the peer teachers were taught what to do during the sessions instead of holding meetings, as in SA and the USA.

\subsection{Clearly articulated and owned vision}

According to Halligan and Donaldson (2001: Online), a well led organisation knows how the vision and values are being communicated effectively to all involved. Therefore, such communication gives staff a common and consistent purpose and clear expectations. It is therefore only when people understand the vision that they will focus their energy in ensuring that the goal is realised. In line with this the SILMG (2008:3) also encourages the vision to be established and articulated to all involved so that all the people can take ownership. In SA, communicating the vision (especially to the students) was deemed significant in ensuring the success of SI for students became a success. Communicating the vision to the first year students was necessary also to inform them about the purpose of the programme. During the orientation session, the students were not only informed about the programme and what it was intended for, but a repeated emphasis was also placed on diligence and hard work on their part, thus encouraging them to develop a sense of responsibility towards their studies (Harding et al., 2011:851) (in ensuring that the programme was a success). The students were therefore made to realise how their commitment towards the programme and embracing the SI vision could make it possible for the institutional goal to be realised (i.e. their performance to be improved). Furthermore, their Supplemental Mathematics Instruction Learning Enhancement (SMILE) programme structure was made convenient for all of them to attend whereby the first hour was used as an introduction to a subsequent tutorial session. The problem however with the first hour session was that students used the venue as a "waiting room" for the subsequent tutorial class and most of them did not contribute to the session at all.

In Nigeria, the vision was also communicated to the students. The students were also made aware of what was expected of them in order for the programme to achieve its goal. The students were expected to attend sessions at all times and the whole institution knew about the programme (Boud, Cohen \& Sampson, 1999:415).

In the USA, the vision was also communicated to students and they were encouraged to attend the sessions. In trying to avoid timetable clashes, many sessions were scheduled and students were requested to attend those that fitted their timetables (Gardner et al., 2005). This indicates that the institution embraced the SI vision and also took ownership of the programme.

The discussions above indicate that in the mentioned countries a similar strategy was applied, namely communicating the programme vision to first year students, and encouraging them to attend these sessions. Resources were made available to the students and many sessions scheduled to avoid timetable clashes. Although this strategy was effective to some extent, this study further seeks to formulate other ways in which to effectively articulate the vision and also to endorse its ownership by all involved as part of enhancing the functionality of SI for students.

\subsection{The use of supplemental instruction strategies}

According to the SISMG (2008:16) the SI leaders need to refrain from "spoon-feeding" the students, re-lecturing, dominating the session and providing all the answers to the students. In other words, SI leaders should allow the students 
to engage freely in conversation in problem solving activities. In this way students' input was valued and by sharing their experience their understanding of the course content will thus increase as well as their performance. In SA, Nigeria and the USA effective SI instructional strategies were also employed.

In SA, the intensive training that the SI leaders received enabled them to help students to integrate course content and learning/study strategies. The training also empowered the SI leaders to assist students with other problem areas such as reviewing of course material covered in lectures, hands on exercises that are unlikely to be utilised in large lecture-classes, discussion based learning that is more difficult to accomplish in large lecture halls, study skills training (e.g. note-taking, textbook use and exam-taking strategies) as well as problem solving (Bowles et al., 2008:5). In the USA and $\mathrm{SA}$, during the mathematics SI sessions the SI leaders required the students to articulate their problem solving approach to teach each other while they solved problems during the SI sessions. At the same time, the SI leaders acted as mere coaches or facilitators rather than instructors, thus eliciting as much as possible, the correct answers from the students without explicitly leading them to the answers (Gardner et al., 2005). In Nigeria however, a different approach was used. The peer-teachers used the demonstration method of teaching whereby they demonstrated to their peers how they solved a mathematical problem (obtained the solutions) and thereafter requested their peers to repeat the routine by demonstrating to the class how the answers were obtained (Bentley et al., 2009:144).

Based on these, the study will thus further look into other ways in which the instructional strategies could be effectively applied in order to enhance SI functionality.

\subsection{Effective student engagement}

According to the SISMG (2009:10) in order for the students to understand the course content, they need to be involved in more than listening. The students also need to be involved in higher order thinking (analysis, synthesis, evaluation etc.) and be engaged in activities (reading, discussing and writing). The guideline further notes that such student engagement will:

- better the students' understanding of the course material,

- increase the students' cognitive processing of the material,

- expose the students to new ideas and more ways of thinking about solving the problem, and

- enable the SI leader to identify the students' misconceptions and gaps in understanding of the material.

Evidence of instances where such student engagement was implemented and consequently improved student understanding of course content and their performance was found in literature.

In SA and the USA, the strategy that was used was to allow students to sit in small groups and the SI leaders would then make use of proactive and participative activities such as "think, pair and share" where students more than anything were encouraged to brainstorm ideas, pair up with another student and discuss their views or approaches to problem solving. In the USA, however, the SI leaders were also trained in questioning techniques based on Bloom's taxonomy which comprises of six levels namely, knowledge (recalling of formulae), comprehension (articulate and comprehend meaning), application (performing operations), analysis (problem solving), synthesis (combining concepts for a deeper meaning) and evaluation (making judgements on the basis of the given data). The SI leaders therefore prepared questions of varied levels of difficulty and also ensured that those questions made participation possible (Fayowski et al., 2008:845).

Although student engagement proved to be effective in assisting students to understand course, in SA one of the biggest challenges experienced was with regard to class capacity. In many instances the sessions were capacitated with many students, and small group instruction was impossible, let alone the SI techniques of collaborative learning (Harding et al., 2011:849).

In Nigeria a different strategy was applied. The course instructors guided the selected peer-teachers through the assignment, providing hints and helping them prepare to present to peer-learning groups. At the end of the session peer students received a quiz and each one in the group was assigned a task to perform (Bentley et al., 2009:144). Ahead of the first session, the first subgroup would prepare a unit which they would then demonstrate to their peers as to how they solved a problem. The second subgroup would then prepare on the second unit and thereafter demonstrate to the first subgroup how they obtained the answers. At that time, the peer teachers took turns pointing out aspects of interest and leading to the discussions among the students (Nnodim, 1997:113).

On the basis of these, the study seeks to discover other effective ways in which to engage the students effectively and meaningfully in their own learning in order to promote understanding of their course content. 


\subsection{Making feedback available to the stakeholders}

The SISMG (2008:46-47) advises that the SI office give regular feedback to the departments/faculties. The guideline also stipulates that immediate feedback be given to the individual SI leaders regarding observations. In this way, the faculties would stay abreast while the feedback provided to the SI leaders would help them develop. Literature also confirms that such a feedback is necessary for SI to be functional.

In SA, evaluations that were conducted took into consideration the inputs from the SI leaders as well. However, some of the concerns raised by the SI leaders were never attended to. For instance, one of the SI leaders' concerns was with regard to the bigger classes they were facilitating which made it difficult for them to adhere to SI techniques of collaborative learning. This was never addressed and the SI leaders thus had to adjust to that by finding their own ways of coping with these circumstances (Harding et al., 2011:851).

In the USA the data that were available from the SI office were shared with both the faculty and the administration as numerical evidence that the programme worked and was producing results. For example, the data that showed that SI needed not to be considered as an additional cost but instead represented an economic savings since the cost of running the programme was modest were also shared with the institution's administrators (Zaritsky et al., 2006:30). Furthermore, data related to what worked and what did not work, were also shared with both the faculty and administration.

In Nigeria, the evaluation and observation processes were conducted and the students' opinions, which also formed part of data, were also allowed. However, the peer teachers whom the students were not satisfied with regarding how they conducted their sessions did not receive such information (Bentley et al., 2009:144). This means that the peerteachers could not reflect on their teaching methods based on feedback from peer students, and consequently no development took place with regard to their teaching role.

The discussion above illustrates the significance of making feedback available to all the stakeholders involved in SA, Nigeria and USA. Moreover, it shows the significance for all involved to reflect on and learn from this feedback. This study will therefore seek to find other, better ways in which feedback can be made available to all involved and to allow those involved to be able to reflect on it.

\section{Conditions Conducive to the Successful Implementation of SI for Students}

The following sections will look into the conditions necessary for the solutions to be effective.

\subsection{Coordinated plan made possible by cooperation between the lecturers and the SI leaders}

The SILMG (2013:10) requires the lecturers and the SI leaders to have meetings prior to the sessions wherein both the SI leaders and the lecturers discuss the content to be covered during the SI sessions. According to Smith (2009: 15), this kind of discussion is important because it helps to maintain student core, facilitates balanced sessions, optimises content coverage and makes it possible to formulate questions that draw from several sections. This will increase students' comprehension of the course content, especially because what is prepared is what students indicated that they do not understand.

In line with this, cooperation between the SI leaders and the lecturers in SA and USA wherein meetings were held weekly enabled both the SI leaders and the lecturers to work as a team. Together, they were able to reflect on content which was difficult to the students and also provided the most apposite strategies that helped students to better learn first year content (Wright et al., 2002:32; Zeger et al., 2006:65). These meetings helped in ensuring that similar concepts were dealt with by the SI leaders at the same time. Through these meetings the SI leaders knew where the lecturers were with the students with regard to content progress and that helped in linking their sessions to what the lecturers did with the students during a lecture. In Nigeria, lessons which were provided to the peer teachers by the course instructors before sessions and alternating the peer teachers' role helped peer teachers to teach their peers more effectively (Bentley et al., 2009:144). The peer-teachers knew what to teach their peers in class and also how to teach them. Furthermore, the teachers were able to teach common topics to the students. As a result, the students benefited from their sessions.

\subsection{Articulated vision and taking ownership thereof}

The SISMG (2013:3) emphasises the need for the SI vision to be embraced. This means that the people involved need to know about it, understand it and also take ownership of the vision. According to the guideline, this is one condition that makes it possible for the programme to achieve its goal (improving student performance). More conditions can be found 
in literature.

In SA and Nigeria, the stakeholders and the students in need of SI were informed about the programme. It was during these information sessions that role players were informed about the nature of their part in the programme. The students (beneficiaries) were encouraged to work diligently and made aware of the importance of doing their part by taking responsibility for their own learning (Harding et al., 2011:851; Krych, March, Bryan, Peake, Pawlina \& Carmichael, 2005:296). Because of the involvement of the faculties that regarded themselves as gate openers rather than gate keepers, in the USA the vision was better embraced by stakeholders (Zaritsky et al., 2006:29). These faculties vigorously promoted the SI vision by articulating its goals and also ensured that the students attended the sessions by continually encouraging them to do so (McGuire, 2006:9). This was done to ensure that the programme's goals were realised. Furthermore, the presence of the course instructor during the SI sessions, facilitating the session together with the SI leader, also promoted student attendance and a sense of honouring the programme's vision. Moreover, the involvement of the campus principal ensured that the course instructors, SI leaders and the coordinators worked together towards the realisation of successful SI for students (Wright et al., 2002:32).

From the above, it is clear that in SA, Nigeria and the USA, the communication and clarification of the programme's vision to the stakeholders helped in ensuring that the stakeholders took ownership of the programme. Ownership of the programme manifested in students attending sessions regularly, lecturers being supportive towards the SI leaders and faculties encouraging student attendance of the sessions.

\subsection{Effective supplemental instruction strategies}

According to the SISMG $(2006: 15)$ the students needed to decide what they need instruction on. On the basis of that, both the lecturer and the SI leader should then decide what needs to be done in order to develop the skills necessary to overcome their hurdles. In line with the above notion, in SA, lecturers and the SI leaders held meetings prior to the SI sessions where they reflected and discussed content that was difficult to the students based on what they observed during the lectures and the SI sessions (Zeger et al.,2006:65). They then came up with strategies which they believed would respond to students' challenges in understanding the content. The formulation of strategies by the lecturers together with the SI leaders thus improved the quality of the SI sessions for students and so the students benefited from those sessions.

In Nigeria, the course instructors guided the selected peer-teachers through assignment, providing hints and helping them prepare to present to peer-learning groups. At the end of the session peer students received a quiz and each one in the group was assigned a task to perform (Bentley et al., 2009:144). The use of the quiz and assigned tasks increased the first year student knowledge of the course.

In the USA, the training offered enabled the SI leaders to act as mere coaches and not the instructors. The sessions which were made longer allowed the students to solve problems in groups. Students were able to articulate their problem solving approach to each other as well as to the SI leader. At the same time, the SI leader who merely acted as the coach rather than a lecturer, got to elicit as much as possible, the correct answers from the students without leading them to the answers. In that way, the students better learned and understood the content (Gardner et al., 2005).

Furthermore, in the USA, more emphasis was placed on the process of learning as a way of equipping students with the necessary skills for continued self-directed enquiry. Students were given an opportunity to discuss any difficulties they experienced in a pro-active manner. In order to master the content, students were given informal quizzes as in Nigeria, to ensure that they were provided with opportunities to determine which content areas were potentially difficult. The most important thing here was that the agenda for the session was determined by the students while the SI leader planned the session in such a way as to enable the students to pinpoint areas that warrant attention (Spencer \& Wallace, 1995:12).

From the above it is clear that in $\mathrm{SA}$, the involvement of the lecturers in the programme made it possible for the $\mathrm{SI}$ leaders to incorporate effective instructional strategies into their session facilitation. Through the frequent meetings they held, the SI leaders learnt which effective instructional strategies to apply during the sessions which will respond to the students' misconceptions regarding certain first year topics. In Nigeria also the guidance which the course instructors provided to the peer-teachers in terms of how they should be facilitating the sessions and which strategies to apply improved the peer teachers' facilitation of the sessions. In the USA, sessions which were extended made it possible for SI collaborative instructional strategies to be applied, e.g. the use of Paired Problem Solving (PPS), Group Problem Solving (GPS), and probing of questions, to mention a few. Despite these positive conditions the study seeks to establish more conditions that will enhance the effectiveness of the instructional strategies. 


\subsection{Effective student engagement}

The SILMG (2013:4 - 5) requires students to be involved in more than listening. It further requires that the students be actively engaged in activities during the sessions in order for them to have a better understanding of the course material and also to have a more cognitive processing of the material. According to the SISMG (2006:6) students who are actively engaged in their own learning acquire an increased retention of what they are learning and also are exposed to new ideas and different ways of thinking about things.

In SA, the SI leaders who were encouraged to actively engage the students in their own learning helped increase the students' understanding of their course. While these students were engaged in their own learning, they also developed better learning skills, strategies and meta-cognitive skills (Bengesai, 2011:61).

In Nigeria, the division of the students into groups wherein group A would be requested to demonstrate to Group B how the answers to the problems were obtained, and vice versa, enhanced students' knowledge. The students' confidence also improved resulting in motivating them to engage in various problem solving exercises, which also increased their understanding of the course content (Nnodim, 1997:112). In the USA, sessions that included time to review the course material covered in lectures, engaging students in hands-on exercises, fully engaging them in discussion based learning that is more difficult to accomplish in large classes, and also in skills training (e.g. note taking, textbook use and exam-taking strategies) helped students to integrate content with study skills and consequently improved students' knowledge of the course content (Bowles et al., 2005:5).

Furthermore, the extension of the SI sessions allowed students to have ample time to actively engage in practical exercises and to regularly practice/study their courses. While students were engaged in problem solving exercises, both the lecturer and the SI leader moved around and helped students with clarity seeking questions. That did not only give the instructor an extra-hand in an overcrowded classroom but it also allowed the SI leader an opportunity to build relationships with students and have a better sense of where they struggle so that he could inform the instructor about content that was difficult to the students (Wright et al., 2002:2). This kind of student engagement assisted students to comprehend the course content.

From the above it is clear that in SA, Nigeria and the USA, the encouragement of SI leaders and peer teachers to engage students in learning enabled students to better comprehend the course content. In the USA, however, the extension of the sessions provided the first year students with ample time to practice. Furthermore, in these countries, the presence of the SI leaders and the lecturers at the time the students were engaged in problem solving exercises, helped students to receive clarity on concepts they found to be challenging.

\subsection{Feedback availability}

The SISMG (2008:46-47) and SISMG (2013:46-47) emphasise the fact that feedback must be made available to all the stakeholders involved. This informs them about the progress of the programme so that they will not be taken by surprise.

In SA and Nigeria feedback from evaluation was obtained and comments by students were read by the SI personnel. This enabled SI personnel to understand the challenges which were experienced even though such information seemed not to have been shared with other people involved in the programme. In Nigeria, however, the course instructors and the peer-teaching administrators were also part of the evaluation process, which was not the case in SA. The students' comments were analysed by both the course instructors and the investigator (Harding et al., 2011:851; Nnodim, 1997:115) with the intention to investigate if they, as the beneficiaries of the programme, received maximum benefit from the programme, and also to identify areas that required modification.

In the USA, writing of the weekly reports by the SI leaders to the SI administrators and the lecturers which also formed part of the evaluation made it possible for more feedback to be available. These reports covered various aspects such as points of confusion for students, students' experiences, methods of explanation and discussion that clarify the lecture and particular student problems and successes which also required serious attention.

The discussion above indicates that in SA feedback was provided only to the SI personnel and not to other stakeholders involved, as was the case in Nigeria and the USA. Feedback provided in these countries did not only reflect student performance of SI attendees versus non-attendees, but also reflected other relevant issues. In the USA, however, unlike in SA and Nigeria, based on the data obtained from the evaluations, the SI leaders received constructive criticisms from the SI coordinator. That assisted them in improving their facilitation of the sessions. 


\section{Threats that Impeded the Successful Implementation of SI for Students at Higher Education Institutions}

The following sections will discuss the threats to the successful implementation of SI.

\subsection{Student lack of motivation and commitment}

In a study conducted in the USA, the following were found to be the most common factors that caused students' low motivation to study certain courses: poor study techniques, insufficient work, inadequate background knowledge, boring presentations of lectures, and a perceived lack of relevance of course content (Anthony, 2000:7-8).

In an effort to address the afore-mentioned issues pertaining to student lack of motivation and commitment several strategies were undertaken. These strategies included increasing academic time, designing curricular strategies to enhance interest in certain courses, and designing and developing specific strategies to involve students in courses related curricular and co-curricular activities.

Creating a curriculum that focused on conceptualising and creating meaning and relevance was also encouraged. Information about mathematics and its utility in future courses and career opportunities in engineering for instance, were made available. Because attitudes and interest also affected achievement, policies and strategies to improve attendance and participation in classroom activities were found worthy to be considered. Giving students appropriate homework assignments were found to stimulate independent engagement in learning tasks. Over and above, the lecturers and SI leaders were encouraged to alter negative attitudes by promoting better classroom practices and providing positive experiences in the course (Singh, Granville \& Dika, 2002:330-331).

\subsection{Limited pool of students from which to find potential SI leaders}

In a study conducted in SA, it was found that the students who became SI leaders were usually those who were majoring in mathematics, and due to the limited number of students it was difficult to properly implement such an extensive programme (Harding et al., 2011:853). The result is that with the number of students who enrolled for first year usually being more than a thousand it was difficult to find qualified and potential SI leaders because of the limited pool to choose from.

In the USA, As part of the solution to address such a challenge, students who were appointed to serve as SI leaders were not only selected from the mathematics majors only, but also from other cohorts such as engineering, provided that they had done the course before and passed it well and that they met the requirements of the programme (Gardner et al., 2005).

\subsection{Insufficient prior knowledge}

According to Arendale (1994:2) SI is more challenging in content areas where prerequisite skills are a key variable. According to Ambrosse, Bridges, DiPietro, Lovett and Norman (2010:12-13) the challenges have always been that sometimes the instructors overestimate the students' prior knowledge and thus build new knowledge on a shaky foundation. It also happens that the students bring prior knowledge to bear that is not appropriate to the context and which is distorting their comprehension. Moreover, the instructors happen to uncover misconceptions and inaccuracies in students' prior knowledge that are actively interfering with their ability to learn new material.

As part of addressing insufficient prior knowledge, students in Nigeria were made to register for courses that were typically connected by an organising theme which gave meaning to their linkage. The reason for doing so was to engender coherent interdisciplinary or cross-subject learning that was not easily attainable through enrolment in unrelated, stand-alone courses (Tinto, 2005:2). The strategy that was used also address the challenge in USA was to engage students in Socratic Learning (SL). In this regard, redirecting of students' questions (RSQ) was used whereby the instructor, instead of stepping in to answer the students' questions, would ask if anyone knew the answer. Another SL strategy used was reciprocal questioning (RQ), an alternating question and answer process that aided students in a deeper understanding of the course content. Concept mapping (CM), whereby students were exposed to a web diagram in order to explore knowledge, brainstorm ideas and organise large amounts of material, was also employed (Painter, Bailey, Gilbert \& Prior, 2006:74). 


\section{Indicators of the Success of an SI Programme}

From literature and the discussions above it is quite clear that SI has a positive impact on student learning and performance. There is substantial evidence that in a well implemented SI, performance and the course grades of the students significantly improved (Etter et al., 2000:356; Fayowski et al., 2008:852), retention rates increased (Zeger et al., 2006:66), and the attrition and failure rates reduced (Zaritsky et al., 2006:23). There is also evidence that such an SI implementation increases student understanding of the course material (Gardner et al., 2005). Furthermore, there is evidence that Sl's well executed plan can benefit all involved (Zeger et al., 2006:63) and help students improve problem solving skills, retain learned concepts and build frameworks for future learning (Ogden, Thompson, Russell \& Simons, 2003:3). Moreover, SI evaluation shows that those who attend SI sessions show more persistence than non-attendees (Hensen et al., 2003:2).

\section{Conclusion}

This paper revealed the challenges experienced with the implementation of SI in institutions of higher education. The paper also presented possible solutions to the challenges and outlined conditions conducive to the implementation of SI in institutions of higher education. The threats that could impede the successful implementation of SI as well as the measures put in place to circumvent them were also briefly mentioned. Lastly, the paper revealed the indicators of success of a well implemented SI in institutions of higher education.

\section{References}

Ambrose, S.A., Bridges, M.W., DiPietro, M., Lovett, M.C., \& Norman, M.K. 2010. How learning works? 7 Research-Based Principles for Smart Teaching. California Jossy Bass: A Willy Imprint.

Anthony, G. 2000. Factors influencing first-year students' success in mathematics. International Journal of Mathematical Education in Science and Technology, 3(11): 3-14.

Arendale D. 1994. Understanding the Supplemental instruction Model. New Directions for Teaching and Learning, 1994(60):1-10.

Bengesai, A. 2011. Engineering students' experiences of Supplemental Instruction: A case study, Alternation, 18(2): 59-77.

Bentley B.S., \& Hill R.V., 2009. Objective and Subjective Assessment of Reciprocal Peer teaching in Medical Gross Anatomy Laboratory. Anatomic Sciences Education, 2(4):143-149.

Boud, D., Cohen, R., \& Sampson, J. (Eds.). 2014. Peer learning in higher education: Learning from and with each other. Routledge.

Bowles, T.T., McCoy, A.C., \& Bates, S.C. 2008. The effect of supplemental instruction on timely graduation. College Student Journal, 42(30): 853-859.

Clarkewood Consulting. 2011. Why do companies have a vision and values statement? New York (http://clarkewoodconsulting.blogspot. com/2011/09/why-do-companies-have-vision-and-values.html) Accessed on 29 April 2014.

Congos, D. H., \& Schoeps, N. 1993. Does supplemental instruction really work and what is it anyway? Studies in Higher Education, 18(2), 165-176.

Coordination. (2000). In Business online dictionary. Retrieved from www.businessdictionary.com/definition/coordination.html

Etter, E.R., Burmeister, S.L. \& Elder, R.J. 2000. Improving students' performance and retention via supplemental instruction. Journal of Accounting, 18(4):355 - 368.

Fayowski, V. \& MacMillan, P.D. 2008. An evaluation of the Supplemental Instruction programme in a first year calculus course. International Journal of Mathematical Education in Science and Technology, 39(7): 843-855.

Gardner, J.F., Moll, A.J., \& Pyke, P.A. 2005. Active Learning in Mathematics: Using the Supplemental instruction Model to improve student success. Paper presented at the American Society for Engineering Education Annual Conference and Exposition.

Halligan, A., \& Donaldson, L. 2001. Implementing clinical governance: turning vision into reality. BMJ: British Medical Journal, 322(7299): 1413.

Harding, A., Engelbrecht, J., \& Verwey, A., 2011. Implementing supplemental instruction for a large group in mathematics. International Journal of Mathematical Education in Science and Technology, 42(2): 847 - 856.

Hensen, K.A., \& Shelley, M.C. 2003. The Impact of Supplemental Instruction: Results From a Large, Public, Midwestern University. Journal of College Student Development, 44(2): 250-259.

Krych, A. J., March, C. N., Bryan, R. E., Peake, B. J., Pawlina, W., \& Carmichael, S. W. 2005. Reciprocal peer teaching: students teaching students in the gross anatomy laboratory. Clinical Anatomy, 18(4): 296-301.

Lockie, N.M. \& Van Lanen, R.J. 2008. Impact of the Supplemental Instruction Experience on Science SI leaders, Journal of Developmental Education, 31(3): 2-12.

Malm, J., Bryngfors, L. \& Mörner, L. L. 2012. Supplemental instruction for improving first year results in engineering studies. Studies in Higher Education, 37(6): 655-666.

McGuire, S.Y. 2006. The Impact of Supplemental Instruction on Teaching Students How to Learn. New Directions for Teaching and Learning, 1(10): 1-8. 
Nnodim, J.0.1997. A controlled trail of peer teaching in a practical gross anatomy. Clinical Anatomy, 10.2:112-117.

Obiunu, J. J. 2008. The effects of reciprocal peer tutoring on the enhancement of career decision making process among secondary school adolescents. Educational Research and Reviews, 3(7): 236-241.

Ogden, P., Thompson, D., Russell, A., \& Simons, C. 2003. Supplemental Instruction: Short- and Long-Term Impact. Journal of Developmental Education, 26(3): 2-8.

Painter, S. L., Bailey, R., Gilbert, M., \& Prior, J. 2006. New directions for supplemental instruction. New Directions for Teaching and learning, 2006(106), 73-84.

SILMG (Republic of South Africa. Nelson Mandela Metropolitan University). 2007. Supplemental Instruction Leader Manual Guideline. Port Elizabeth: NMMU

SILMG (Republic of South Africa. Nelson Mandela Metropolitan University). 2008. Supplemental Instruction Leader Manual Guideline. Port Elizabeth: NMMU

SILMG (Republic of South Africa. Nelson Mandela Metropolitan University). 2013 Supplemental Instruction Leader Manual Guideline. Port Elizabeth: NMMU

Singh, K., Granville, M. \& Dika, S., 2002. Mathematics and Science achievement: Effects of Motivation, Interest, and Academic Engagement. The Journal of Educational Research, 6(95): 323 - 332.

SISMG (Republic of South Africa. Nelson Mandela Metropolitan University). 2006. Supplemental Instruction Supervisor Manual Guideline. Port Elizabeth: NMMU

SISMG (Republic of South Africa. Nelson Mandela Metropolitan University). 2007. Supplemental Instruction Supervisor Manual Guideline. Port Elizabeth: NMMU

SISMG (Republic of South Africa. Nelson Mandela Metropolitan University). 2008. Supplemental Instruction Supervisor Manual Guideline. Port Elizabeth: NMMU

SISMG (Republic of South Africa. Nelson Mandela Metropolitan University). 2010. Supplemental Instruction Supervisor Manual Guideline. Port Elizabeth: NMMU

Spencer, G. \& Wallace, J. 1995. Helping Students to Learn from Each Other supplemental instruction. Staff and educational development association

Tinto, V. 2005. Taking Student Success Seriously: Rethinking the First Year of College. Ninth Annual Intersession Academic Affairs Forum

Wong, J.G., Waldrep, T.D., \& Smith, T.G. 2007. Formal Peer-Teaching in Medical School Improves Academic Performance: The MUSC Supplemental Instructor Program, teaching and Learning in Medicine: An International Journal, 3(19): 216-220.

Wright, L., Wright, R.R. \& Lamb, C.E. 2002. Developmental Mathematics Education and Supplemental Instruction: Pondering the Potential, 26 (1):30-35.

Zaritsky, J.S. \& Toce, A. 2006. Supplemental Instruction at a Community College: The Four Pillars. New Directions for Teaching and Learning. 2006(106): 23-31.

Zeger, S., Clark-Unite, C. \& Smith, L. 2006. How Supplemental Instruction Benefits Faculty, Administration and Institutions. New Directions for Teaching and Learning, 2006(106):63 - 72. 